\title{
Origin and evolution of eusociality: A perspective from studying primitively eusocial wasps
}

\section{RAGHAVENDRA GADAGKAR}

Centre for Ecological Sciences and Centre for Theoretical Studies, Indian Institute of Science, Bangalore 560 012, India

MS received 24 April 1990

\begin{abstract}
Eusocial insects are those that show overlap of generations, cooperative brood care and reproductive caste differentiation. Of these, primitively eusocial insects show no morphological differences between reproductive and worker castes and exhibit considerable flexibility in the social roles that adult females may adopt. This makes them attractive model systems for investigations concerning the origin of eusociality. The rapidly accumulating information on primitively eusocial wasps suggests that haplodiploidy is unlikely to have an important role in the origin of eusociality. General kin selection (without help from haplodiploidy) could however have been an important factor due to the many advantages of group living. Pre-imaginal caste bias leading to variations in fertility is also likely to have some role. Because workers often have some chance of becoming reproductives in future, mutualism and other individual selection models suggest themselves as important factors. A hypothesis for the route to eusociality which focuses on the factors selecting for group living at different stages in social evolution is presented. It is argued that group living originates owing to the benefit of mutualism (the 'Gambling Stage') but parental manipulation and subfertility soon become important (the 'Manipulation Stage') and finally the highly eusocial state is maintained because genetic asymmetries created by haplodiploidy are exploited by kin recognition (the 'Recognition Stage').
\end{abstract}

Keywords. Social insects; evolution of eusociality; primitively eusocial wasps; haplodiploidy; Hymenoptera.

\section{Introduction}

When animals behave in a fashion that increases the genetic fitness of any conspecific other than their own offspring while lowering their own fitness, such behaviour is termed altruistic. Any form of altruism constitutes an obvious challenge to Darwin's theory of natural selection which expects animals to behave selfishly. A major goal of sociobiology is to explain the evolution of such altruistic behaviour within the framework of the theory of natural selection. Social insects which provide the most extreme forms of altruism and were recognized by Darwin himself (Darwin 1859, pp. 268-273) as posing a serious challenge to his theory have quite naturally been the focus of most attention in this regard. Animals that live in groups or colonies comprising at least two generations, cooperate in brood care and exhibit caste differentiation into a fertile reproductive caste (usually referred to as the queen) and a sterile worker caste are termed eusocial (Michener 1969; Wilson 1971).

With the exception of the naked mole-rat that lives in underground tunnels in Africa (Jarvis 1981), eusociality is restricted to insects. Among insects, eusociality has only been achieved by termites, ants and some bees and wasps. With the exception of one or two species of sphecids (Matthews 1968, 1990; Ross and Matthews 1989), all eusocial wasps belong to the family Vespidae. This family is 
divided into three subfamilies, namely Stenogastrinae, Polistinae and Vespinae. The Stenogastrinae have been relatively poorly studied (but see Turillazzi 1990). The Vespinae represent a generally more advanced level of sociality and are termed highly eusocial because of marked and consistent morphological differences between the reproductive and non-reproductive castes (see Greene 1990, Matsuura 1990). That leaves the Polistinae, a rather large group consisting of 29 genera and about 850 species. Based on behaviour and nest architecture, the Polistinae are divided into two subgroups, the independent-founding and the swarm-founding Polistinae (Jeanne 1980). Swarm-founding Polistinae (consisting of 24 genera and some species of the genus Ropalidia) live in large colonies (often with 1000 or more adults) and have correspondingly large nests, sometimes with several tiers of combs covered by an envelope. New colonies are always initiated by queens in the company of workers. Compared to independent-founding polistines, the swarmfounding species show a relatively higher level of sociality. Queens and workers are often morphologically differentiated, at least in size, and queens often use a pheromonal means of controlling worker behaviour and reproduction (for a recent review, see Jeanne 1990).

Independent-founding is seen in the four genera Belonogaster, Mischocyttarus, Parapolybia and Polistes as well as some species of the genus Ropalidia. Independent-founding polistines live in relatively small colonies (rarely exceeding 100 adult wasps) and construct small, simple, unenveloped combs normally suspended by a narrow pedicel. Queens initiate new colonies either singly or in small groups but without the aid of workers. It is easy to argue that the independent-founding Polistinae are perfect model systems for investigating the evolution of eusociality. Small colonies make it possible to mark and study every adult wasp and the open combs hide nothing from the observer. In many species, the nests are quite abundant and are often built in remarkably accessible places the doors and window sills of our homes, representing the acme of accessibility. A relatively primitive level of eusociality characterized by the lack of morphological caste differentiation, an essentially behavioural mechanism of queen control and considerable flexibility in social roles of adult wasps make these species especially attractive. Not surprisingly, independent-founding polistines have been the subjects of increasing attention in the last 15-20 years and have perhaps contributed as much as or more than any other group of social insects to the formulation and testing of ideas concerning evolution of eusociality (for recent reviews, see Gadagkar 1990a; Reeve 1990).

\section{Primitively eusocial wasps as model systems}

Why do these wasps live in groups? Why do some individuals accept the role of a sterile worker? During colony founding, why do some individuals nest with others even if it means few or no opportunities to lay their own eggs? During the early post-emergence phase of the colony cycle, why do many females stay to help their mothers produce more offspring? It is the opportunity to ask such questions that makes primitively eusocial polistine wasps such attractive model systems in insect sociobiology.

In most highly eusocial insects such as honey bees, termites, and most ants, the simple answer to these questions could be that individuals who accept sterile 
worker roles have no other choice; over evolutionary time they have lost the ability to reproduce on their own. Workers in some species are capable of laying eggs, but with rare exceptions (e.g., the cape honeybee; see Anderson 1963) they lay only haploid, male-producing eggs, and even then such worker reproduction is usually suppressed in the presence of the queen (Page and Erickson 1988;. Ratneiks 1988; Ratneiks and Visscher 1989; Visscher 1989). The primary questions of interest for highly social species, then, concern how advanced social organizations originate and how they are maintained. An answer to the first question requires evidence of events that might have happened millions of years ago or studies of other groups which are perhaps "inventing" complex sociality today. An answer to the second question seems harder to come by. Advanced social organizations may be maintained today because the advantages present during their origin are still prevalent. Alternatively, these may simply represent evolutionary cul-de-sacs from which return to more egalitarian societies or solitary life is difficult.

In dealing with primitively eusocial species, we are probably on slightly better ground. There are several situations in which the animals have opportunities for direct reproduction. Single- and multiple-foundress colonies coexist. Subordinate females adopt the role of the queen if the most dominant female is lost or removed (Jeanne 1972; Litte 1979, 1981; Gadagkar 1987). Daughters sometimes challenge, drive away, and replace mother queens (Jeanne 1972; Yamane 1986; R. Gadagkar, unpublished). Groups of females may leave their natal nests to found new colonies (Gadagkar and Joshi 1984, 1985). All these facts strongly suggest that individuals accept subordinate roles not because they are incapable of doing anything else but because social life, even if it means partial or total sterility, must sometimes be more advantageous than solitary life.

\section{The evolution of eusociality}

Much has been written about the evolutionary forces that mould sociality in insects (Hamilton 1964a, b, 1972; Wilson 1971, 1975; Lin and Michener 1972; Alexander 1974; West-Eberhard 1975, 1978, 1987; Crozier 1977; Evans 1977; Charnov 1978; Starr 1979, 1985; Craig 1980; Jeanne 1980; Andersson 1984; Brockmann 1984; Fletcher and Ross 1985; Gadagkar 1985a, b; Joshi and Gadagkar 1985; Itô 1986a, 1987; Hansell 1987; Queller and Strassmann 1988), but there has also been criticism for not adequately distinguishing between the origin of sociality and its subsequent maintenance (Stubblefield and Charnov 1986). Such a distinction is not always easy to make, but it can be argued that one way to focus on the origin of social life is to study primitively eusocial species where real choices concerning reproductive roles exist.

How can social life be more advantageous than solitary life if the former means sterility? This seemed impossible until the advent of the concept of inclusive fitness (Hamilton 1964a, b). Today, it is common practice to include in any calculation of fitness, both direct transmission of genes to future generations via offspring production and indirect transmission via caring for relatives. The selection of any trait that depends wholly or partly on the indirect pathway is often called kin selection. Thus sterile individuals in social groups may have opportunities to gain fitness via the indirect route if the group consists of close kin. We may broadly generalize Hamilton's (1964a, b) concept of inclusive fitness and say that group life is favoured over solitary life if 


$$
\sum_{i=1}^{n} r_{i}>\frac{1}{2} m,
$$

where $n$ is the number of individuals (offspring or other relatives) reared in the group mode, $r_{i}$ is the coefficient of genetic relatedness to these individuals and $m$ is the number of offspring reared in the solitary mode.

\section{The haplodiploidy hypothesis}

One way in which the inequality in (1) may be obtained is for $r_{i}$ to be greater than $\frac{1}{2}$, that is, for genetic relatedness to other relatives to be greater than that to offspring. This may potentially be achieved with a haplodiploid genetic system, where genetic relatedness between a female and her full-sisters is 0.75 , which is greater than the value between a female and her daughters $(r=0.5)$. Since an overwhelming number of the origins of eusociality have occurred in the insect order Hymenoptera, in which haplodiploidy is universal, much attention has been paid to the possibility that haplodiploidy predisposes Hymenopterans to eusociality. This so-called haplodiploidy hypothesis requires several conditions, however. Colonies should consist of a single egg-layer mated to a single male so that workers need not rear any half-sisters or more distantly related individuals. Workers must either successfully skew investment in favour of their sisters or must be able to rear their own sons instead of brothers. The latter condition is necessary because workers are related to their brothers by only 0.25 while they are related to their sons by 0.5 .

Many features of the biology of primitively eusocial wasps suggest that these conditions may not always be met. In Belonogaster petiolata, only $15 \%$ of foundress associations consist exclusively of former nestmates, so that cofoundresses probably are not often closely related (Keeping and Crewe 1987). Even when they are, subordinate cofoundresses are at best sisters of the egg-layer and are thus helping raise nieces and nephews $(r=0.375)$. In many species, queen supersedure (Pardi 1948; West-Eberhard 1969; Jeanne 1972; Metcalf and Whitt 1977; Gamboa et al. 1978; Yamane 1986; Gadagkar et al. 1990b) must act to reduce relatedness between workers and the brood they rear. Polygyny, or the simultaneous presence of more than one egg-layer, has been reported in Mischocyttarus mexicanus fall nests (Litte 1977), Ropalidia cyathiformis (Gadagkar and Joshi 1982, 1984), Ropalidia variegata jacobsoni (Yamane 1986) and Ropalidia fasciata (Itô 1986b). Nests are frequently usurped by foreign conspecifics in Mischocyttarus flavitarsis (Litte 1979). These factors should also considerably reduce worker-brood relatedness. Finally, multiple mating by the egg-layer is known in Ropalidia marginata (Muralidharan et al. 1986), so that even when daughters are working solely for their mothers they may be rearing mixtures of full- and half-sisters. Levels of intra-colony genetic relatedness determined using electrophoretic separation of isozymes are now available for 19 species of primitively eusocial wasps (Gadagkar 1990b). Of the 13 species for which estimates with standard error are available, only 2 species have values high enough for $r_{i}$ in that group mode to be greater than $\frac{1}{2}$ (Gadagkar 1990b, c, d).

Polygyny or multiple mating by the queen should pose no great difficulty for the haplodiploidy hypothesis if workers discriminate between full-sisters and less related individuals, giving preferential aid to the former (Gadagkar 1985b). However, studies of nestmate discrimination suggest that the labels and templates used in discrimination are not produced individually, but rather are acquired from 
a common external source, namely the natal nest or nestmates, making it unlikely that different levels of genetic relatedness can be effectively recognized among members of the same colony (Gadagkar 1985b; Gamboa et al. 1986; Venkataraman et al. 1988; Queller et al. 1990). Thus it seems likely that workers in these primitively eusocial wasps often rear complex mixtures of full-sisters, half-sisters, nieces, daughters, brothers, nephews, sons, and cousins, and probably do so without the ability to discriminate on the basis of genetic relatedness. Because $r$ in such societies rarely exceeds $\frac{1}{2}$, it has been increasingly suspected that haplodiploidy is not as important a factor in the origin of insect sociality as was thought earlier (Evans 1977; West-Eberhard 1978; Andersson 1984; Stubblefield and Charnov 1986; Venkataraman et al. 1988; Gadagkar 1990b, c, d).

Even if $r_{i}$ is rarely much greater than $\frac{1}{2}$, the inequality in (1) can nonetheless be achieved if $n>m$; indeed, this is true even if $r$ in the group mode is smaller than $\frac{1}{2}$, provided $n$ is that much greater than $m$. The ecology of independent-founding polistine wasps suggests that there must be substantial benefits to group living, that is, $n$ must often be greater than $m$. For instance, the probability of survival of singlefoundress colonies is certainly small, as the nest and its brood are extremely vulnerable to predators and parasites and to usurpation by conspecifics (e.g., Gamboa 1978; Suzuki and Murai 1980). Yet the effectiveness of protection from such enemies by even one or two supernumerary adults is obvious to anyone who has watched these wasp colonies. Furthermore, multiple foundresses are more likely to be able to re-build a damaged nest than are single foundresses. This latter factor favours multiple-foundress nests even when the destructive agent is itself indifferent to group size, as in the case of predation by birds or destruction by typhoons (Litte 1977, 1979, 1981; Itô 1986b; Strassmann et al. 1988). The origin of eusociality therefore probably has much more to do with such benefits of group living and associated gains in inclusive fitness than with haplodiploidy. This is sometimes called general kin selection to distinguish it from the role of haplodiploidy in facilitating kin selection.

\section{Parental manipulation or the subfertility hypothesis}

There is another way by which the inequality in (1) may be attained, without the involvement of haplodiploidy. Ecological conditions may exist in which a parent who manipulates a fraction of her offspring into being sterile and helping rear her remaining (fertile) offspring leaves behind more grandchildren than her wild-type counterpart. This idea, often known as the parental manipulation hypothesis, was first suggested by Alexander (1974). A significant problem with this is whether counter-selection on the offspring would be successful in making them overcome parental manipulation. A related idea which gets around this problem is the subfertility hypothesis of West-Eberhard (1975), which simply reminds us that subfertile females produced by whatever cause (even by accidental variation in the quantity of food obtained as larvae) will find it 'easier' to give up reproduction and accept a worker role. That is, their $m$ will be so small that the inequality in (1) may be satisfied rather easily. The general ideas embodied in the parental manipulation and subfertility hypotheses have found support in theoretical (Stubblefield and Charnov 1986), modelling (Craig 1979, 1983), and empirical (Michener and Brothers 1974) studies, and there seems to be little doubt that subfertility caused by parental 
manipulation or other factors plays a major role in maintaining eusociality in highly social insects.

As far as primitively eusocial wasps are concerned, the role of parental manipulation or subfertility has scarcely been tested. Instead, it is common to assume that caste is determined entirely in the adult stage (e.g., Brian 1980; Roseler et al 1980; Wheeler 1986; Queller and Strassmann 1989; Reeve 1990). There is however, some indirect evidence of pre-imaginal caste bias in Polistes fuscatus (Gibo 1974), Belonogaster griseus (Pardi and Marino Piccioli 1981) and Mischocyttarus (Hunt 1988, 1990). Besides, recent experiments with $R$. marginata permit rejection of the null hypothesis that "all eclosing females are potentially capable of becoming egg-layers". Of 299 freshly eclosed females of $R$. marginata tested, only 149 built nests and laid eggs while the remaining 150 died without doing so inspite of living, on the average, significantly longer than the mean time taken by the egg-layers to start laying eggs. Moreover, there were two rather interesting correlates of becoming egglayers: (1) the number of empty cells that the queen had left unfilled with eggs in the nest from which they had eclosed, and (2) their own rate of food intake during the experiment. These results have been interpreted to mean that when the queen of a colony is young and healthy or otherwise in the phase of worker production, her influence on the colony would be high and thus the brood would develop into adults programmed to feed less and have a low probability of becoming egg-layers. Conversely, when the queen of a colony is old and weak or otherwise in the phase of queen production, her influence on the colony is expected to be low and the brood is thus expected to develop into adults programmed to feed more and have a high probability of becoming egg-layers (Gadagkar et al. 1988, 1990). It therefore appears that subfertility may contribute significantly towards achieving the inequality in (1).

\section{Mutualism or individual selection hypothesis}

The presence of permanently sterile worker castes is the most prominent and seemingly paradoxical feature of highly eusocial insects. Not surprisingly, most theories for the evolution of sociality attempt to explain the attainment of this crucial property. Somewhat unfortunately though, such a tendency has sometimes obscured the rather obvious fact that many social insect species do not possess permanently sterile workers but could nevertheless be forerunners of the highly eusocial state. The evolutionary forces promoting the origin of such primitive levels of sociality may thus be quite different from those discussed above and may not reveal themselves under an excessive concentration on total sterility. The statements that "... social behavior in insects is in part mutualistic" and that "social colonies without altruism are therefore considered a probability" (Lin and Michener 1972, p. 131) may well prove to have been prophetic. The theory of reciprocal altruism proposed by Trivers (1971), which suggests that aid may be given 'today' with the hope of getting a return 'tomorrow', has for some mysterious reason seldom been applied to social insect colonies.

A related kind of individual selection model has been discussed by WestEberhard (1978) and Gadagkar (1985a). Consider two wasps that come together and nest jointly. If their joint productivity (say, 21 offspring) is even slightly greater than the sum of their individual productivities (say, $10+10=20$ offspring) in the 
solitary mode, and if the roles of queen and sterile worker are assigned randomly, then wasps who take the risk of joint nesting will, on average, produce 10.5 offspring and thereby do better than those who shy away from the risks of joint nesting. In this "Gambling" model, benefits of group living can be infinitesimally small, and abilities of parents to manipulate their offspring or of colony members to discriminate on the basis of differential genetic relatedness are not necessary. Many features of primitively eusocial species such as simultaneous or serial polygyny, queen supersedure, nest usurpation, colony fission, behavioural caste differentiation, the differentiation of potential queens and the occasional presence of non-nestmates in foundress associations lend credibility to the idea that sociality may arise due to the benefits of mutualism, reciprocal altruism and "Gambling".

\section{A hypothesis concerning the route to eusociality}

It is sometimes stated that haplodiploidy, parental manipulation, and mutualism are not mutually exclusive and that they may all have had a place in shaping the evolution of insect societies. Such a statement is perhaps of little value unless one can assign more specific roles to each force (theory). I shall now propose a hypothesis concerning the route to eusociality that will do just that. I propose that there are three sequential stages in the evolution of eusociality (figure 1). It seems reasonable that the initial incentive for group living comes from mutualism, reciprocal altruism, and the benefits of "Gambling". I shall call this the Gambling

\section{THE ROUTE TO EUSOCIALITY}

\section{THE GAMBLING STAGE II. THE MANIPULATION STAGE III. THE RECOGNITION STAGE}

\begin{tabular}{|c|c|c|}
\hline $\begin{array}{l}\text { Group nesting is } \\
\text { lor mutual benefit. } \\
\text { Either all individuals } \\
\text { lay eggs or the egg } \\
\text { layer is decided by } \\
\text { chance. An average } \\
\text { individual does } \\
\text { better than a solitary } \\
\text { one. } \\
\text { E.g., Mony presocial } \\
\text { ond some primitively } \\
\text { eusocial wasps and } \\
\text { bees }\end{array}$ & $\begin{array}{l}\text { Accidental voriations } \\
\text { in fertilities are } \\
\text { exploited to usurp } \\
\text { egg-laying } \\
\text { opportunities by } \\
\text { some individuals } \\
\text { or } \\
\text { some individuals are } \\
\text { manipulated into } \\
\text { subfertile and } \\
\text { subordinate roles } \\
\text { E.g. Some primitively } \\
\text { eusocial wasps and } \\
\text { bees }\end{array}$ & $\begin{array}{l}\text { Genetic asymmetries } \\
\text { created by } \\
\text { haplodiploidy are } \\
\text { exploited by showing } \\
\text { preferential altruism } \\
\text { toward close relatives } \\
\text { Sulficient inclusive } \\
\text { fitness is thus } \\
\text { gained to compensate } \\
\text { for reduced } \\
\text { opportunities for } \\
\text { reproduction } \\
\text { E. g., Many onts, } \\
\text { honey bees. }\end{array}$ \\
\hline
\end{tabular}

Figure 1. The route to eusociality, a hypothesis concerning the evolution of the highly eusocial state from the solitary state through the Gambling, Manipulation, and Recognition stages. The examples given for each stage are tentative as our knowledge of the causes and consequences of group living in most social insect groups is rather sketchy. 
Stage. This stage requires no preadaptation for intra-group manipulation or for recognition of genetic relatedness, although group living among kin (who might come together merely by virtue of being neighbours) will evolve more easily (WestEberhard 1978; Schwarz 1988). The only prerequisite for the evolution of incipient societies by mutualism is a sufficiently complex behavioural repertoire to permit the necessary interactions; solitary wasps seem to possess an appropriately diverse array of behaviours (Tinbergen 1932, 1935; Tinbergen and Kruyt 1938; Brockmann and Dawkins 1979; Brockmann et al. 1979). It is easy to imagine that many presocial wasps much as those listed in West-Eberhard (1978) and described by West-Eberhard (1987) and Wcislo et al. (1988) are either already at this stage or are immediate forerunners of this stage.

Once group living is established, the stage is set for the second stage which I shall call the Manipulation Stage. Accidental variations in food supply leading to subfertility can now be exploited and the ability to manipulate offspring or other nestmates can be selected for. As manipulation becomes increasingly effective, benefits of group living become increasingly unavailable to some individuals who begin to lose reproductive options and get trapped into worker roles. It is precisely at this stage that the ability to recognize and give preferential aid to closer relatives will begin to have selective value. This is the final stage which I shall call the Recognition Stage. In other words, I propose that the benefits of haplodiploidy for social evolution become available at this final stage.

This hypothesis explains one otherwise curious fact. Although kin recognition and nestmate discrimination studies have a long way to go, there is a growing impression that primitively eusocial species may not have the ability to discriminate between different levels of genetic relatedness once all the individuals (the less and the more related ones) are part of the same colony. On the other hand, there are at least some examples among highly eusocial species such as honey bees and ants where there is clear evidence of the ability to distinguish between levels of relatedness within a colony (reviewed in Gadagkar 1985b, Venkataraman et al. 1988; see also Page et al. 1989, Queller et al. 1990). If haplodiploidy was important for the origins of insect sociality one would expect workers in primitively eusocial species to exploit the genetic asymmetries thus created by discriminating between close and distant relatives. But if the origin of eusociality is due to mutualistic benefits, as assumed here, and its subsequent maintenance in highly eusocial forms is due largely to haplodiploidy, the observed distribution of kinship discrimination abilities is no longer a paradox. Indeed, it is difficult to imagine how the ability to manipulate conspecifics or to discriminate between different levels of genetic relatedness among conspecifics (of the same sex) would have had selective value prior to the advent of group living.

The problem of the route to eusociality has received considerable attention in the past (Wilson 1971). William Morton Wheeler (Wheeler 1923, 1928) who was greatly influenced by the early studies on wasps, formally proposed and championed the so called "subsocial" route. This hypothesis envisages that colonies with extended maternal care are starting points for the ultimate evolution of the habit of the daughters to stay back and help their mother produce more offspring. Realising the obvious inappropriateness of this hypothesis for many bees, Michener (1958; see also Lin and Michener 1972, Michener 1974) proposed the "semisocial" route and argued that associations of adults of the same generation rather than a family unit 
containing two generations is a more likely starting point. More recently, WestEberhard (1978; see also Carpenter 1989, 1990) has modified the semisocial hypothesis and proposed the "polygynous family" hypothesis, which insists that the starting point must have consisted of close relatives. The route to eusociality proposed in this paper is consistent with each of the three hypotheses mentioned above. But it differs from these hypotheses in that its focus is not on the kinds of individuals or colonies that occur in different stages in evolution but on the selective advantages of group living that must have sustained social evolution at different stages. Because the kinds of colonies or associations do not necessarily specify the selective advantages that promote them, such a focus is important. To take just one example, groups of females of the same generation may only find it worthwhile to form a colony if every individual has a certain probability of laying eggs. On the other hand, a colony may consist of daughters helping their mothers produce more offspring but the daughters may be selected to stay back and help their mothers only if there is a certain probability of their eventually taking over the role of egg-layer in that colony.

\section{Conclusion}

Our understanding of the origin and evolution of eusociality is bound to go through many more twists and turns. It is also possible that eusociality has arisen by different routes and for different reasons in different groups. For this reason, perspectives from studying diverse eusocial groups are important. Our present knowledge (admittedly very limited and biased) of primitively eusocial wasps suggests that the advantages of mutualism, reciprocal altruism and "Gambling" are likely to have been more important than haplodiploidy in the origin of eusociality. The maintenance of eusociality is another matter however. Although primitively eusocial wasps cannot tell us much about this, it seems likely that haplodiploidy has a significant role to play in the maintenance of the highly eusocial stage.

\section{Acknowledgement}

I thank Madhav Gadgil and N. V. Joshi for comments on an earlier draft of this paper. Supported in part by a grant from the Department of Science and Technology, Government of India.

\section{References}

Alexander R. D. 1974 The evolution of social behaviour. Annu. Rev. Ecol. Syst. 5: 325-83

Anderson R. H. 1963 The laying worker in the Cape honey bee, Apis mellifera capensis. J. Apic. Res. 2: 85-92

Andersson M. 1984 The evolution of eusociality. Annu. Rev. Ecol. Syst. 15: 165-189

Brian M. V. 1980 Social control over sex and caste in bees, wasps and ants. Biol. Rev. 55: 379-415

Brockmann H. J. 1984 The evolution of social behaviour in insects. In Behavioural ecology: An evolutionary approach, 2nd edn (eds) J. R. Krebs and N. B. Davies (Sunderland, Mass: Sinauer) pp. $340-361$

Brockmann H. J. and Dawkins R. 1979 Joint nesting in a digger wasp as an evolutionarily stable preadaptation to social life. Behaviour 71: 204-245 
Brockmann H. J., Grafen A. and Dawkins R. 1979 Evolutionarily stable nesting strategy in a digger wasp. J. Theor. Biol. 77: 473-496

Carpenter J. M. 1989 Testing scenarios: Wasp social behaviour. Cladistics 5: 131-144

Carpenter J. M. 1990 Phylogenetic relationships in the Vespidae. In Social biology of wasps (eds) K. G. Ross and R. W. Matthews (Ithaca, NY: Cornell University Press) (in press)

Charnov E. L. 1978 Evolution of eusocial behavior: Offspring choice or parental parasitism? J. Theor. Biol. 75: 451-465

Craig R. 1979 Parental manipulation, kin selection, and the evolution of altruism. Evolution 33: 319-334

Craig R. 1980 Sex ratio changes and the evolution of eusociality in the Hymenoptera: Simulation and games theory studies. J. Theor. Biol. 87: 55-70

Craig R. 1983 Subfertility and the evolution of eusociality by kin selection. J. Theor. Biol. 100: 379-397

Crozier R. H. 1977 Evolutionary genetics of the Hymenoptera. Annu. Rev. Entomol. 22: 263-288

Darwin C. 1859 The origin of species (New York: Collier, 1962)

Evans H. E. 1977 Extrinsic versus intrinsic factors in the evolution of insect sociality. Bioscience 27: 613-617

Fletcher D. J. C. and Ross K. G. 1985 Regulation of reproduction in eusocial Hymenoptera. Annu. Rev. Entomol. 30: 319-343

Gadagkar R. 1985a Evolution of insect sociality -A review of some attempts to test modern theories. Proc. Indian Acad. Sci. (Anim. Sci.) 94: 309-324

Gadagkar R. 1985b Kin recognition in social insects and other animals-A review of recent findings and a consideration of their relevance for the theory of kin selection. Proc. Indian Acad. Sci. (Anim. Sci.) 94: $587-621$

Gadagkar R. 1987 Social structure and the determinants of queen status in the primitively eusocial wasp Ropalidia cyathiformis. In Chemistry and biology of social insects, Proceedings of the $X$ International Congress of IUSSI (eds) J. Eder and H. Rembold (Munich: Verlag J. Peperny) pp. 377-378

Gadagkar R. 1990a Belonogaster, Mischocyttarus, Parapolybia and independent founding Ropalidia. In Social biology of wasps (eds) K. G. Ross and R. W. Matthews (Ithaca, NY: Cornell University Press) (in press)

Gadagkar R. 1990b On testing the haplodiploidy hypothesis for the evolution of eusociality in the Hymenoptera. Behav. Ecol. Sociobiol. (submitted)

Gadagkar R. 1990c The haplodiploidy threshold and social evolution. Curr. Sci. 59: 374-376

Gadagkar R. 1990d A test of the role of haplodiploidy in the evolution of hymenopteran eusociality. In Social insects and the environment. Proceedings of the 11th International Congress of IUSSI (eds) G. K. Veeresh, B. Mallik and C. A. Viraktamath (New Delhi: Oxford and IBH) pp. 539-540

Gadagkar R., Bhagavan S., Malpe R. and Vinutha C. 1990a On reconfirming the evidence for preimaginal caste bias in a primitively eusocial wasp. Proc. Indian Acad. Sci. (Anim. Sci.) 99: 141-150

Gadagkar R., Chandrashekara K., Chandran S. and Bhagavan S. 1990b Serial polygyny in Ropalidia marginata: Implications for the evolution of eusociality. In Social insects and the environment. Proceedings of the 11th International Congress of IUSSI (eds) G. K. Veeresh, B. Mallik and C. A. Viraktamath (New Delhi: Oxford and IBH) pp. 227-228

Gadagkar R. and Joshi N. V. 1982 Behaviour of the Indian social wasp Ropalidia cyathiformis on a nest of separate combs (Hymenoptera, Vespidae). J. Zool. (London) 198: 27-37

Gadagkar R. and Joshi N. V. 1984 Social organisation in the Indian wasp, Ropalidia cyathiformis (Hymenoptera, Vespidae). Z. Tierpsychol. 64: 15-32

Gadagkar R. and Joshi N. V. 1985 Colony fission in a social wasp. Curr. Sci. 54: 57-62

Gadagkar R., Vinutha C., Shanubhogue A. and Gore A. P. 1988 Pre-imaginal biasing of caste in a primitively eusocial insect. Proc. R. Soc. London B233: 175-189

Gamboa G. J. 1978 Intraspecific defense: Advantage of social cooperation among paper wasp foundresses. Science 199: 1463-1465

Gamboa G. J., Heacock B. D. and Wiltjer S. L. 1978 Division of labor and subordinate longevity in foundress associations of the paper wasp Polistes metricus (Hymenoptera: Vespidae). J. Kans. Entomol. Soc. 51: 343-352

Gamboa G. J., Reeve H. K. and Pfenning D. W. 1986 The evolution and ontogeny of nestmate recognition in social wasps. Annu. Rev. Entomol. 31: 431-454

Gibo D. L. 1974 A laboratory study on the selective advantage of foundress associations in Polistes fuscatus (Hymenoptera: Vespidae). Can. Entomol. 106: 101-106

Greene A. 1990 Dolichovespula and Vespula. In Social biology of wasps (eds) K. G. Ross and R. W. Matthews (Ithaca, New York: Cornell University Press) (in press) 
Hamilton W. D. 1964a The genetical evolution of social behaviour I. J. Theor. Biol. 7: 1-16

Hamilton W. D. 1964b The genetical evolution of social behaviour II. J. Theor. Biol. 7: 17-52

Hamilton W. D. 1972 Altruism and related phenomena, mainly in social insects. Annu. Rev. Ecol. Syst. 3: 192-232

Hansell M. 1987 Nest building as a facilitating and limiting factor in the evolution of eusociality in the Hymenoptera. Oxford surveys in evolutionary biology 4: 155-181

Hunt J. H. 1988 Lobe erection behavior and its possible social role in larvae of Mischocyttarus paper wasps. J. Insect Behav. 1: 379-386

Hunt J. H. 1990 Nourishment and the evolution of social Vespidae. In Social biology of wasps (eds) K. G. Ross and R. W. Mathews (Ithaca, NY: Cornell University Press) (in press)

Itô Y. 1986a On the pleometrotic route of social evolution in the Vespidae. Monit. Zool. Ital. (N.S.) 20: 241-262

Itô Y. 1986b Social behaviour of Ropalidia fasciata (Hymenoptera: Vespidae) females on satellite nests and on a nest with multiple combs. J. Ethol. 4: 73-80

Itô Y. 1987 Role of pleometrosis in the evolution of eusociality in wasps. In Animal societies: Theories and facts (eds) Y. Itô, J. L. Brown and J. Kikkawa (Tokyo: Japan Sci. Soc. Press) pp. 17-34

Jarvis J. U. M. 1981 Eusociality in a mammal: Cooperative breeding in naked mole-rat colonies. Science. 212: $571-573$

Jeanne R. L. 1972 Social biology of the neotropical wasp Mischocyttarus drewseni. Bull. Mus. Comp. Zool. Harv. Univ. 144: 63-150

Jeanne R. L. 1980 Evolution of social behaviour in the Vespidae. Annu. Rev. Entomol. 25: 371-396

Jeanne R. L. 1990 The swarm-founding Polistinae. In Social, biology of wasps (eds) K. G. Ross and R. W. Matthews (Ithaca, NY: Cornell University Press) (in press)

Joshi N. V. and Gadagkar R. 1985 Evolution of sex ratios in social hymenoptera: Kin selection, local mate competition, polyandry and kin recognition. J. Genet. 64: 41-58

Keeping M. G. and Crewe R. M. 1987 The ontogeny and evolution of foundress associations in Belonogaster petiolata (Hymenoptera: Vespidae). In Chemistry and biology of social insects, Proceedings of the $X$ International Congress of IUSSI (eds) J. Eder and H. Rembold (Munich: Verlag J. Peperny) pp. 383-384

Lin N. and Michener C. D. 1972 Evolution of sociality in insects. Q. Rev. Biol. 47: 131-159

Litte M. 1977 Behavioural ecology of the social wasp, Mischocyttarus mexicanus. Behav. Ecol. Sociobiol. 2: $229-246$

Litte M. 1979 Mischocyttarus flavitarsis in Arizona, social and nesting biology of a Polistine wasp. Z. Tierpsychol. 50: 282-312

Litte M. 1981 Social biology of the polistine wasp, Mischocyttarus labiatus: Survival in a Colombian rain forest. Smithson. Contrib. Zool. 327: 1-28

Matsuura M. 1990 Vespa and Provespa. In Social biology of wasps (eds) K. G. Ross and R. W. Matthews (Ithaca, NY: Cornell University Press) (in press)

Matthews R. W. 1968 Microstigmus comes: sociality in a sphecid wasp. Science. 160: 787-788

Matthews R. W. 1990 Evolution of social behaviour in sphecid wasps. In Social biology of wasps (eds) K. G. Ross and R. W. Matthews (Ithaca, NY: Cornell University Press) (in press)

Metcalf R. A. and Whitt G. S. 1977 Relative inclusive fitness in the social wasp Polistes metricus. Behav. Ecol. Sociobiol. 2: 353-360

Michener C. D. 1958 The evolution of social behaviour in bees. Proc. X Int. Congr. Entomol. (Montreal) 2: $441-448$

Michener C. D. 1969 Comparative social behaviour of bees. Annu. Rev. Entomol. 14: 299-342

Michener C. D. 1974 The social behavior of the bees: A comparative study. (Cambridge, Mass: Harvard University Press)

Michener C. D. and Brothers D. J. 1974 Were workers of eusocial Hymenoptera initially altruistic or oppressed? Proc. Natl. Acad. Sci. USA 71: 671-674

Muralidharan K., Shaila M. S. and Gadagkar R. 1986 Evidence for multiple mating in the primitively eusocial wasp Ropalidia marginata (Lep.) (Hymenoptera: Vespidae). J. Genet. 65: 153-158

Page R. E. Jr., and Erickson E. H. Jr. 1988 Reproduction by worker honey bees. Behav. Ecol. Sociobiol. 23: $117-126$

Page R. E. Jr., Robinson G. E. and Fondrk M. K. 1989 Genetic specialists, kin recognition and nepotism in honey-bee colonies. Nature (London) 338: 576-579

Pardi L. 1948 Dominance order in Polistes wasps. Physiol. Zool. 21: 1-13

Pardi L. and Marino Piccioli M. T. 1981 The biology of Belonogaster (Hymenoptera, Vesidae): 4. Caste 
differences in Belonogaster griseus and the position of this genus among social wasps. Monit. Zool. Ital. (suppl.) 14: 131-146

Queller D. C., Hughes C. R. and Strassman J. E. 1990 Wasps fail to make distinctions. Nature (London) 344: 388

Queller D. C. and Strassman J. E. 1988 Reproductive success and group nesting in the paper wasp, Polistes annularis. In Reproductive success (ed) T. H. Clutton-Brock (Chicago: Chicago University Press)

Queller D. C. and Strassmann J. E. 1989 Measuring inclusive fitness in social wasps. In The genetics of social evolution (eds) M. D. Breed and R. E. Page (Boulder, Co: West-view) pp. 103-122

Ratnieks F. L. W. 1988 Reproductive harmony via mutual policing by workers in eusocial hymenoptera. Am Nat. 132: 217-236

Ratnieks F. L. W. and Visscher P. K. 1989 Worker policing in the honeybee. Nature (London) 342: 796-797

Reeve H. K. 1990 Polistes. In Social biology of wasps (eds) K. G. Ross and R. W. Matthews (Ithaca, NY: Cornell University Press) (in press)

Roseler P. F., Roseler I. and Strambi A. 1980 The activity of corpora allata in dominant and subordinated females of the wasp Polistes gallicus. Insectes Soc. 27: 97-107

Ross K. G. and Matthews R. W. 1989 Population genetic structure and social evolution in the sphecid wasp Microstigmus comes. Am. Nat. 134: 574-598

Schwarz M. P. 1988 Intra-specific mutualism and kin-association of cofoundresses in allodapine bees. Monit. Zool. Ital. (in press)

Starr C. K. 1979 Origin and evolution of insect sociality: A review of modern theory. In Social insects (ed.) H. R. Hermann (New York: Academic Press) vol. 1, pp. 35-79

Starr C. K. 1985 Enabling mechanisms in the origin of sociality in the Hymenoptera-The sting's the thing. Ann. Entomol. Soc. Assoc. 78: 836-840

Strassmann J. E., Queller D. C. and Hughes C. R. 1988 Predation and the evolution of sociality in the paper wasp Polistes bellicosus. Ecology 69: 1497-1505

Stubblefield J. W. and Charnov E. L. 1986 The origin of eusociality. Heredity 55: 181-187

Suzuki H. and Murai M. 1980 Ecological studies of Ropalidia fasciata in Okinawa island, Japan: I. Distribution of single foundress and multiple foundress colonies. Res. Popul. Ecol. (Kyoto) 22: 184-195

Tinbergen N. 1932 Ueber die Orientisrung des Bienenwolfes (Philanthus triangulum Fabr.) Zs. vergl. Physiol. 16: 30534 [Translated into English and reprinted in: N. Tinbergen 1972 The animal in its world, field studies (Cambridge, Mass: Harvard University Press) vol. 1, pp. 103-127]

Tinbergen N. 1935 Ueber die Orientierung des Bienewolfes (Philanthus triangulum Fabr.) II. Die Bienenjagd. Zs. Vergl. Physiol. 21: 699716 [Translated into English and reprinted in: N. Tinbergen 1972 The animal in its world, field studies (Cambridge, Mass: Harvard University Press) vol. 1, pp. 128-145]

Tinbergen N. and Kruyt W. 1938 Ueber die Orientierung des Bienenwolfes (Philanthus triangulum Fabr.) III. Die Bevorzugung bestimmter Wegmarken. Zs. Vergl. Physiol. 25: 292-334 [Translated into English and reprinted in: N. Tinbergen 1972 The animal in its world, field studies (Cambridge, Mass: Harvard University Press) vol. 1, pp. 146-196]

Trivers R. L. 1971 The evolution of reciprocal altruism. Q. Rev. Biol. 46: 35-57

Turrillazi S. 1990 The Stenogastrinae. In Social biology of wasps (eds) K. G. Ross and R. W. Matthews (Ithaca, NY: Cornell University Press) (in press)

Venkataraman A. B., Swarnalatha V. B., Padmini N. and Gadagkar R. 1988 The mechanism of nestmate discrimination in the tropical social wasp Ropalidia marginata and its implications for the evolution of sociality. Behav. Ecol. Sociobiol. 23: 271-279

Visscher P. K. 1989 A quantitative study of worker reproduction in honey-bee colonies. Behav. Ecol. Sociobiol. 25: 247-254

Wcislo W. T., West-Eberhard M. J. and Eberhard W. G. 1988 Natural history and behaviour of a primitively 'social wasp, Auplopus semialatus, and its parasite, Irenangelus eberhardi (Hymenoptera: Pompilidae). J. Insect Behav. 3: 247-260

West-Eberhard M. J. 1969 The social biology of Polistine wasps. Misc. Publ. Mus. Zool. Univ. Mich. 140: $1-101$

West-Eberhard M.'J. 1975 The evolution of social behaviour by kin selection. Q. Rev. Biol. 50: 1-33

West-Eberhard M. J. 1978 Polygyny and the evolution of social behavior in wasps. J. Kans. Entomol. Soc. 51: 832-856 
West-Eberhard M. J. 1987 Flexible strategy and social evolution. In Animal societies: Theories and facts (eds) Y. Itô, J. L. Brown and J. Kikkawa (Tokyo: Japan Sci. Soc. Press) pp. 35-51

Wheeler D. E. 1986 Developmental and physiological determinants of castes in social Hymenoptera: evolutionary implications. Am. Nat. 128: 13-34

WheeIer W. M. 1923 Social life among the insects. (New York: Harcourt, Brace)

Wheeler W. M. 1928 The social insects: their origin and evolution. (London: Kegan, Paul, Trench, Trubner)

Wilson E. O. 1971 The insect societies (Cambridge, Mass: Harvard University Press)

Wilson E. O. 1975 Sociobiology (Cambridge, Mass: Harvard University Press)

Yamane S. 1986 The colony cycle of the Sumatran paper wasp Ropalidia (Icariola) variegata jacobsoni (Buysson), with reference to the possible occurrence of serial polygyny (Hymenoptera Vespidae). Monit. Zool. Ital. 20: 135-161 